\title{
BMJ Open Level of vital and laboratory values on arrival, and increased risk of 7-day mortality among adult patients in the emergency department: a population- based cohort study
}

\author{
Peter Bank Pedersen (DD ,1,2 Daniel Pilsgaard Henriksen, ${ }^{3}$ Mikkel Brabrand, ${ }^{1,4}$ \\ Annmarie Touborg Lassen (1) ${ }^{1,5}$
}

To cite: Pedersen PB, Henriksen DP, Brabrand M, et al. Level of vital and laboratory values on arrival, and increased risk of 7-day mortality among adult patients in the emergency department: a populationbased cohort study. BMJ Open 2020;10:e038516. doi:10.1136/ bmjopen-2020-038516

- Prepublication history and supplemental material for this paper are available online. To view these files, please visit the journal online (http://dx.doi. org/10.1136/bmjopen-2020038516).

Results from this study were accepted for Abstract and Poster Presentation at the 40th International Symposium on Intensive Care and Emergency Medicine in Brussels, Belgium 24-27 March 2019, postponed due to COVID-19.

Received 13 March 2020 Revised 15 July 2020 Accepted 11 October 2020

Check for updates

(c) Author(s) (or their employer(s)) 2020. Re-use permitted under CC BY-NC. No commercial re-use. See rights and permissions. Published by BMJ.

For numbered affiliations see end of article.

Correspondence to Mr Peter Bank Pedersen; peter.bank.pedersen@rsyd.dk

\section{ABSTRACT}

Objectives The aim of the study was to provide evidence for, at which vital and laboratory values, increased risk of 7-day mortality in acute adult patients on arrival to an emergency department (ED).

Design A population-based cohort study.

Setting ED at Odense University Hospital, Denmark. Participants All patients $\geq 18$ years with a first-time contact within the study period, 1 April 2012 to 31 March 2015.

Primary and secondary outcome measures Primary outcome was 7-day all-cause mortality. Variables were first recorded vital and laboratory values included in risk stratification scores; respiratory frequency, blood pressure, heart rate, Glasgow Coma Scale, temperature, saturation, creatinine, $\mathrm{PaO}_{2}$, platelet count and bilirubin. The association between values and mortality was described using a restricted cubic spline. A predefined 7-day mortality of $2.5 \%$ was chosen as a relevant threshold.

Results We included 40423 patients, $52.5 \%$ women, median age 57 (IQR 38-74) years and 7-day mortality $2.8 \%$. Seven-day mortality of $2.5 \%$ had thresholds of respiratory frequency $<12$ and $>18 / \mathrm{min}$, systolic blood pressure $<112$ and $>192 \mathrm{~mm} \mathrm{Hg}$, heart rate $<54$ and $>102$ beats $/ \mathrm{min}$, temperature $<36.0^{\circ} \mathrm{C}$ and $>39.8^{\circ} \mathrm{C}$, saturation $<97 \%$, Glasgow Coma Scale score $<15$, creatinine $<41$ and $>98 \mu \mathrm{mol} / \mathrm{L}$ for $\mathrm{PaO}_{2}<9.9$ and $>12.3 \mathrm{kPa}$, platelet count $<165$ and $>327 \times 10^{9} / \mathrm{L}$ and bilirubin $>12 \mu \mathrm{mol} / \mathrm{L}$.

Conclusion Vital values on arrival, outside the normal ranges for the measures, are indicative of increased risk of short-term mortality, and most of the value thresholds are included in the lowest urgency level in triage and risk stratification scoring systems.

\section{INTRODUCTION}

\section{Background}

On arrival to an emergency department (ED), patients are diverse, not grouped or categorised and in very different states of disorders. Abnormal vital values are shown to be a
Strengths and limitations of this study

- The study included all acutely ill adult patients with a first-time contact within a 3-year study period.

- Due to the Danish population-based registers, we presented $100 \%$ follow-up.

- The patients were included on arrival and represented a very diverse group of conditions and diseases.

- We had no data on treatment on arrival, which could affect the vital and laboratory values included.

- It was a single-centre study, which might limit the generalisability.

prognostic factor of unfavourable outcomes as short-term mortality and intensive care unit admission. ${ }^{1-3}$ Furthermore, these abnormal values result in high urgency levels in triage systems, ${ }^{4}$ are predictive of rapid response team activation, ${ }^{56}$ and repeated vital value measurements are able to identify patients at risk of deterioration. ${ }^{78}$

With few exceptions, ${ }^{9}$ studies on vital and laboratory values are conducted outside the $\mathrm{ED}^{10}$ or are restricted to selected populations divided into specific groups based on diagnoses or symptoms. ${ }^{11}$ This does not resemble the diverse clinical reality on patient arrival to an ED doorstep. ${ }^{7}$

Associations between each individual value on arrival to an ED and increased risk of deterioration or even mortality are unknown and are supported by little to no evidence. ${ }^{12}$ Triage systems are used in the evaluation of patients in the ED. Common to these are threshold values, defining different urgency levels or clinical state of the patient, which guides clinicians in their decision-making of whom to treat first. ${ }^{4}{ }^{13-18}$ But are these threshold values correct? Or are they leading to treatments without benefit, or leaving patients 
without the right treatment and in risk of deterioration or even death?

We aimed to provide evidence for, at which values, increased risk of 7-day all-cause mortality in acute adult patients on arrival to an ED.

\section{Objectives}

To identify thresholds of increased risk of 7-day mortality among adult acute patients, according to vital and laboratory values, measured on or straight after arrival to an ED.

\section{METHODS}

This study was reported based on the Strengthening the Reporting of Observational Studies in Epidemiology (STROBE) statement and the STROBE explanation and elaboration. ${ }^{1920}$ Excerpts of this section were published as part of a previous paper. ${ }^{21}$

\section{Design and setting}

We conducted an observational 3-year population-based follow-up study at the ED of Odense University Hospital, covering all adult patients arriving from April 2012 to March 2015.

In Denmark, healthcare services are free of charge for all residents, including consultation at primary care physicians, public prehospital emergency services and public hospital treatments, as part of the tax-funded welfare system covering the entire population.

Odense University Hospital is a 1000-bed university teaching hospital covering all medical specialties and serves as the only hospital for a mixed rural-urban population of 230000 adults including four municipalities. ${ }^{22}$ The ED is a level 1 trauma centre and acts as the primary emergency entrance for all adult patients except patients diagnosed with severe cardiac disease in the prehospital setting, patients with ongoing nephrological or haematological treatment, patients on oncological therapy and women in active labour. The ED provides 24-hour emergency care and receives approximately 65000 contacts per year.

The patients arrived by public prehospital emergency service or were allocated by a primary care physician who acted as a gatekeeper for non-obvious acute patients. ${ }^{23} \mathrm{On}$ arrival, all patients, except patients who presented with minor trauma, had their vital values measured. Patients had their laboratory tests performed, and following the initial clinical evaluation some patients had their arterial blood gases performed. Patients were evaluated primarily by a specialised nurse, and the ED practised a five-level Danish Emergency Process Triage based on complaints and vital values. ${ }^{2425}$

\section{Participants}

Eligible patients were all adult acute patients ( $\geq 18$ years) arriving to the ED within the study period. They were included at first contact within the study period to evade bias from repeated measurements, and we evaluated their first measured vital and laboratory values. The registered date of contact was defined as index date. Patients were excluded if they lived outside the hospital's primary catchment area, were unidentified or registered with an invalid identification number. Furthermore, patients in the lowest triage category, blue (minor injuries, such as a sprained ankle or small cuts), and consequently not evaluated with vital or laboratory value measurements were omitted from the analysis.

Follow-up was based on Danish nationwide registers from index date to death or 7 days, whichever came first. ${ }^{26} 27$

The study population is all adult people living in four clearly defined municipalities that represent the primary catchment area of Odense University Hospital.

\section{Outcome and variables}

Primary outcome was predefined as 7-day (short-term) all-cause mortality. Exposure variables were selected with inspiration from the Sequential Organ Failure Assessment Score, ${ }^{16}$ and were first recorded vital values within 6 hours of arrival to the ED; respiratory frequency (RF), blood pressure, heart rate, Glasgow Coma Scale (GCS), temperature, peripheral $\mathrm{O}_{2}$ saturation (saturation) and first achievable laboratory values within 24 hours of arrival; creatinine, $\mathrm{PaO}_{2}$, platelet and bilirubin.

Furthermore, we included individual-level variables such as age, gender and Charlson Comorbidity Index (CCI).

\section{Data sources}

Laboratory values data were extracted from the hospital's laboratory database. Vital values were extracted from electronic patient records, and with the aim to minimise selection bias we conducted a manual review of all electronic records without a complete set of vital values, to fill in the missing data. The unique Danish personal identification number, assigned to all Danish citizens since 1968, was used to identify all patients and to combine individual patient data from different registers nationwide. ${ }^{28}$ Data from the Central Person Register were used for information regarding gender, time of birth and death. ${ }^{26}$ The Danish National Patient Registry contains data on all hospital admissions since 1995 in Denmark, and data were collected on patient demographics and comorbidities (Charlson Index based on the last 10 years of discharge diagnosis before index date). ${ }^{27} 29$

\section{Statistical methods}

Baseline characteristics were presented as numbers and percentages. Data were presented as means, SD, medians and 25th and 75th percentiles (range) where appropriate. Proportions were presented with $95 \%$ CIs based on binomial distribution. CCI and age were grouped into four: 0 , 1,2 and $>2$, and $18-44,45-64,65-84$ and $>84$ years of age on arrival to the ED. Furthermore, baseline characteristics were presented for 7-day survivors and non-survivors as online supplemental 1. 
The association between vital and laboratory values and mortality was described using a restricted cubic spline with 4-5 knots to include continuous variables without categorisation and assumption of linearity in a regression model. ${ }^{30}{ }^{31}$ With a large sample size and high number of different values more df were possible, and 5 knots were preferable. ${ }^{3233}$ The spline was fit by selecting knots where the curves came together, and the curves were restricted to be linear at the tails to avoid unstable estimates. To bring focus away from the tails, the cubic spline curves on laboratory values are pictured without the extremities, but the complete graphs are available as online supplemental 2. GCS was treated as a categorical variable and presented as a bar chart. As relevant thresholds for increased risk we chose a predefined 7-day mortality rate of $2.5 \%$ just below the average overall 7-day mortality and performed sensitivity analyses for 7-day mortality rates at $5 \%$.

Missing data were left out of the analysis on defining thresholds for low-risk short-term mortality. Furthermore, missing data were treated as an independent variable in sensitivity analysis, to point out risk of short-term mortality in case of variables missing on arrival.

All statistical analysis and plots were performed using Stata V.16.0 (StataCorp, Texas, USA).

\section{Patient and public involvement}

No patient was involved.

\section{RESULTS}

A total of 40423 individual patients had a first-time contact within the study period (figure 1), $52.5 \%$ were women, median age was 57 (IQR 38-74) and 7-day mortality was $2.8 \%$. Basic characteristics including missing data were presented in table 1 and grouped in 7-day survivors and non-survivors in online supplemental 1.

\section{Vital values}

After constructing unadjusted logistic regression restricted cubic splines, for the different vital values except GCS, four of the five splines presented a u-shaped relationship between the values and 7-day mortality. For RF the 7-day mortality increased around 14-15 breaths/ min, increased further around 10 and 30 breaths $/ \mathrm{min}$ and the $2.5 \%$ thresholds were $<12$ and $>18 / \mathrm{min}$. According to systolic blood pressure, the 7-day mortality increased around 110 and $210 \mathrm{~mm} \mathrm{Hg}$, increased more around 100 $\mathrm{mm} \mathrm{Hg}$ and the increased risk thresholds were $<112$ and $>192 \mathrm{~mm} \mathrm{Hg}$. The thresholds for heart rate were $<54$ and $>102$ beats/min, and the mortality increased around 60 and 120 beats/min and increased further around 40 and 140 beats/min. We presented an increased risk of 7-day mortality according to temperature $<36.0^{\circ} \mathrm{C}$ and $>39.8^{\circ} \mathrm{C}$. Seven-day mortality increased by decreasing temperature below $36^{\circ} \mathrm{C}$, and increased further at temperatures below $35^{\circ} \mathrm{C}$.

The relationship between values and 7-day mortality for saturation turned out descending and the threshold for $2.5 \%$ 7-day mortality was $<97 \%$. The threshold for $2.5 \%$ 7 -day mortality for GCS was $<15$ (figure 2 ).

Table 2 presents summary statistics of the different thresholds identified by the logistic regression models, including sensitivity, specificity, positive predictive value and likelihood ratios. A sensitivity analysis for 7-day mortality of $5 \%$ indicated an increasing specificity and likelihood ratio, but a decreasing sensitivity (online supplemental 3).

\section{Laboratory values}

Restricted cubic splines were constructed for four different blood tests and the unadjusted model discovered a u-shaped relationship between three of the variables and 7-day mortality. The thresholds for an increased 7-day mortality at $2.5 \%$ were for creatinine $<41$ and $>98$ $\mu \mathrm{mol} / \mathrm{L}$, the risk increased around 60 and $90 \mu \mathrm{mol} / \mathrm{L}$ and increased further around $100 \mu \mathrm{mol} / \mathrm{L}$. According to $\mathrm{PaO}_{2}$ the thresholds were $<9.9$ and $>12.3 \mathrm{kPa}$, and the mortality increased below 10 and above $13 \mathrm{kPa}$. For platelet count the increased risk thresholds were $<165$ and $>327 \times 10^{9} / \mathrm{L}$,

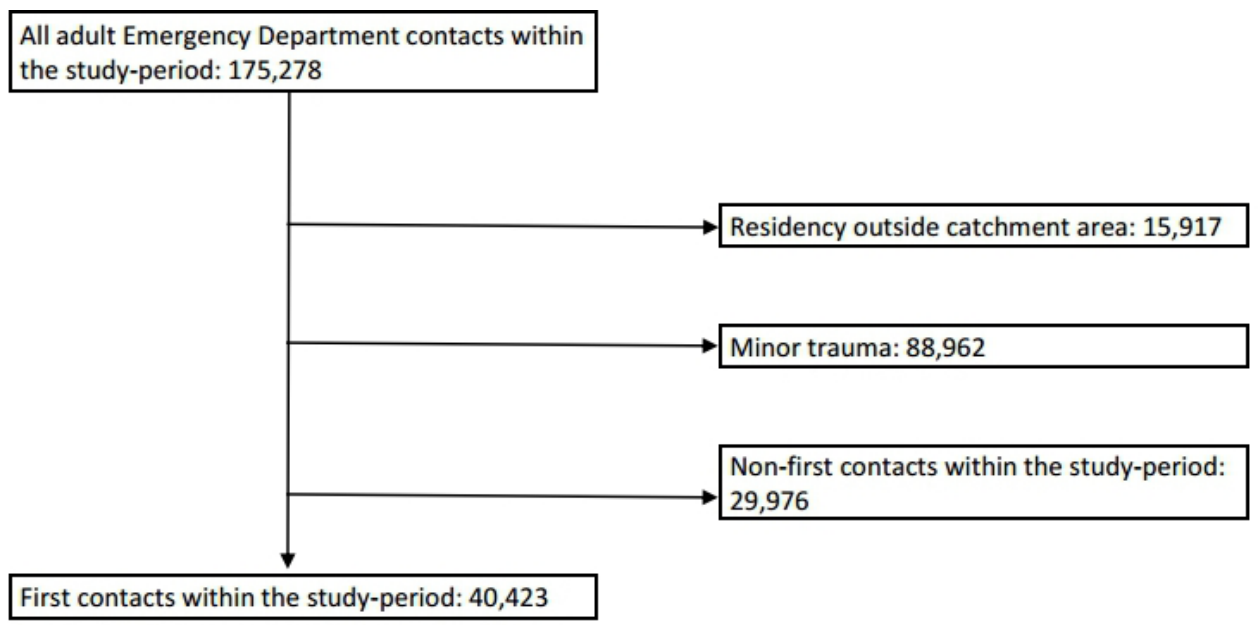

Figure 1 Flow chart from all contacts to patients with a first-time contact within the 3-year study period. Previously presented in another study. ${ }^{21}$ 
Table 1 Baseline characteristics of all first-time contacts within the study period. Parts of the baseline characteristics were previously presented in another study ${ }^{21}$

\begin{tabular}{|c|c|c|}
\hline & & All patients on arrival \\
\hline Patients & $\mathrm{n}(\%)$ & $40423(100)$ \\
\hline Age (years) & Median (IQR) & $57(38-74)$ \\
\hline \multirow[t]{2}{*}{ Gender } & Female (\%) & $21239(52.5)$ \\
\hline & Male (\%) & $19184(47.5)$ \\
\hline \multirow[t]{4}{*}{ Age groups (years) } & $18-44(\%)$ & $13189(32.6)$ \\
\hline & $45-64(\%)$ & $10971(27.1)$ \\
\hline & $65-84(\%)$ & $12478(30.9)$ \\
\hline & $>84(\%)$ & $3785(9.4)$ \\
\hline \multirow[t]{4}{*}{ Charlson Comorbidity Index } & $0(\%)$ & $24236(60.0)$ \\
\hline & $1(\%)$ & $6775(16.8)$ \\
\hline & $2(\%)$ & $4335(10.7)$ \\
\hline & $>2(\%)$ & $5077(12.6)$ \\
\hline \multirow[t]{10}{*}{ Values } & Respiratory frequency, mean $\pm \mathrm{SD}$ ( $\mathrm{n}=$ missing) & $17 \pm 4(7718)$ \\
\hline & Systolic blood pressure, mean $\pm S D$ ( $n=$ missing) & $139 \pm 25(4371)$ \\
\hline & Heart rate, mean $\pm S D$ ( $n=$ missing) & $85 \pm 19(4368)$ \\
\hline & Glasgow Coma Scale, median (IQR) $(\mathrm{n}=$ missing) & $15(15-15)(5834)$ \\
\hline & Temperature, mean $\pm \mathrm{SD}$ ( $\mathrm{n}=$ missing) & $36.8 \pm 0.9(8701)$ \\
\hline & Saturation, median (IQR) ( $\mathrm{n}=$ missing) & $98(96-100)(5873)$ \\
\hline & Creatinine, median (IQR) ( $n=$ missing) & $78(65-95)(7104)$ \\
\hline & $\mathrm{PaO}_{2}$, median $(\mathrm{IQR})(\mathrm{n}=$ missing) & $10.5(8.9-12.6)(29479)$ \\
\hline & Platelet, median (IQR) ( $\mathrm{n}=$ missing) & $240(196-294)(13$ 009) \\
\hline & Bilirubin, median (IQR) ( $\mathrm{n}=$ missing) & $9(6-13)(10838)$ \\
\hline
\end{tabular}

and the 7-day mortality increased around 150 and $300 \times 10^{9} / \mathrm{L}$, and increased extra below $150 \times 10^{9} / \mathrm{L}$. For bilirubin, the 7-day mortality increased around $10 \mu \mathrm{mol} / \mathrm{L}$, and the increased risk of 7-day mortality threshold was $>12 \mu \mathrm{mol} / \mathrm{L}$ (figure 3 and table 2).

For vital and laboratory values the percentage of missing data was between $10.8 \%$ and $72.9 \%$. Summary statistics in predicting 7-day mortality if missing were presented in online supplemental 4.

\section{DISCUSSION}

Our study presented vital and laboratory value thresholds according to increased risk of 7-day mortality based on a predefined 7 -day mortality rate at $2.5 \%$, which were just below 7-day mortality in the study cohort. We found that the level of vital and laboratory values associated with increased 7-day all-cause mortality in most cases was either at the level within the ranges of clinically used normal values or at a level related to a low acuity score in clinically applied triage and risk stratification scoring systems. ${ }^{4013-1834-41}$

With a sensitivity from $30 \%$ to $60 \%$ and specificity from $60 \%$ to $90 \%$, none of the investigated values had the strength by themselves to identify all patients at increased risk of short-term mortality, which is in line with earlier conclusions on single markers. ${ }^{42} 43$

Our study demonstrates the value of determining the association with mortality across the full range of available values for these variables rather than assigning discrete inadequate thresholds through systems and scores, which are occasionally used in a binary way to evaluate if a patient is critically ill and in need of immediate treatment. The foundation for triage systems and scores are very diverse. The process of development for the ED is for some systems inadequate, but still the systems are validated and used in numerous places. ${ }^{4131424}$ Others are based on the intensive care setting by consensus, ${ }^{1634}$ or on admission to hospital empirically based on mortality. ${ }^{29} 44$

When looking at the different values, the upper risk threshold according to RF resembled the mean RF in ED population patients ${ }^{45}$ and was below the threshold reported elsewhere. ${ }^{1015} 46$ Our threshold of increased risk of 7-day mortality according to systolic blood pressure was higher or equal to what was reported in earlier studies, ${ }^{1547-50}$ and for heart rate our threshold was almost in accordance with or lower than earlier results. ${ }^{10} 18$ Other studies have, in line with our study, presented low temperature with increased short-term mortality, but thresholds were predefined. ${ }^{36} 5152$ Furthermore, with 
A: Respiratory Frequency

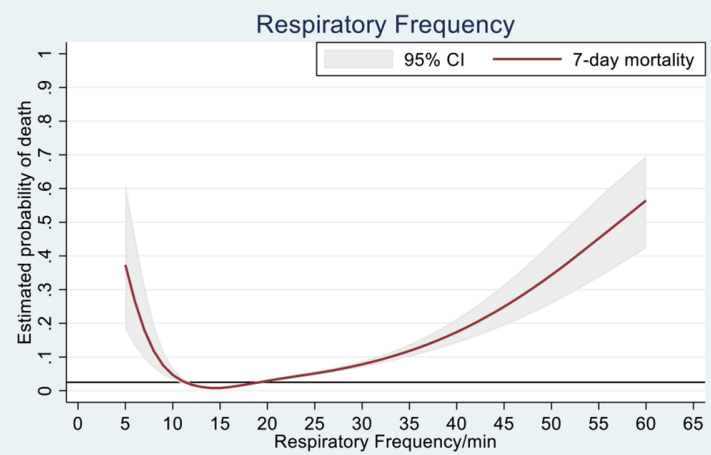

C: Heart Rate

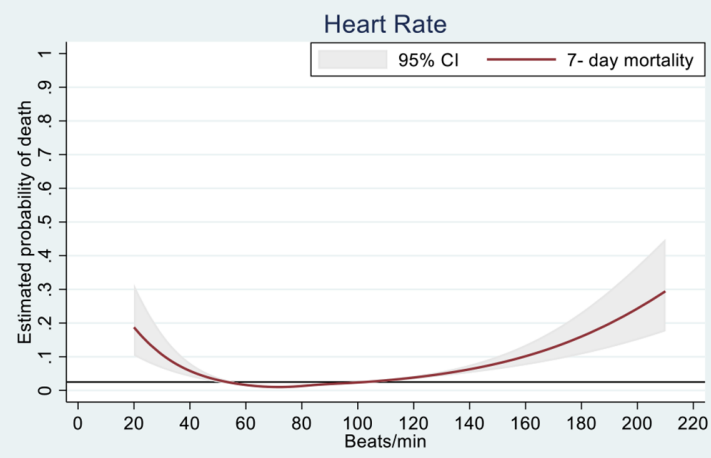

E: Saturation

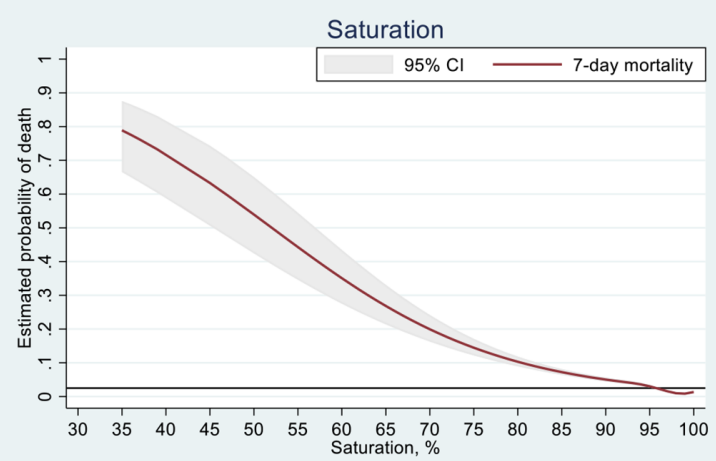

B: Systolic Blood Pressure

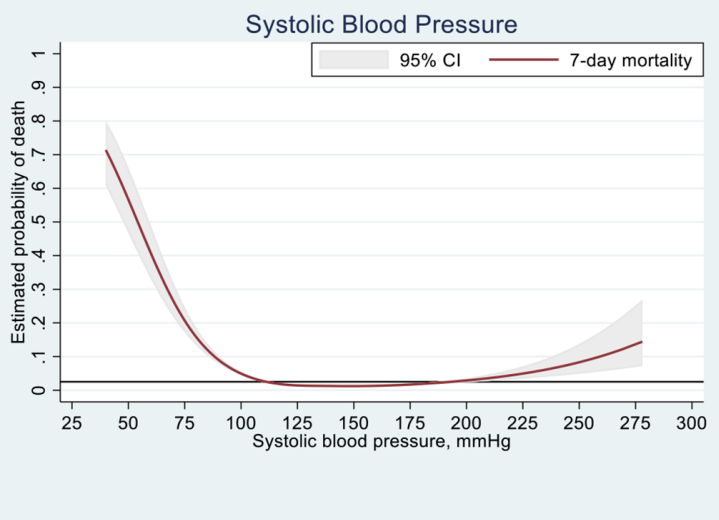

D: Temperature

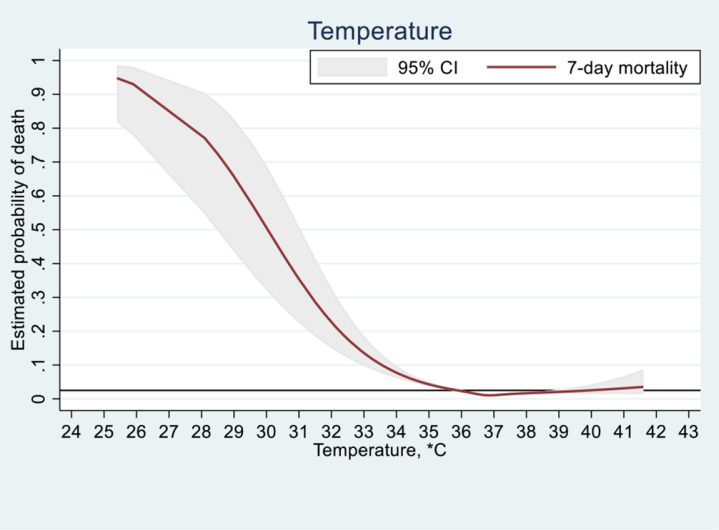

F: Glasgow Coma Scale

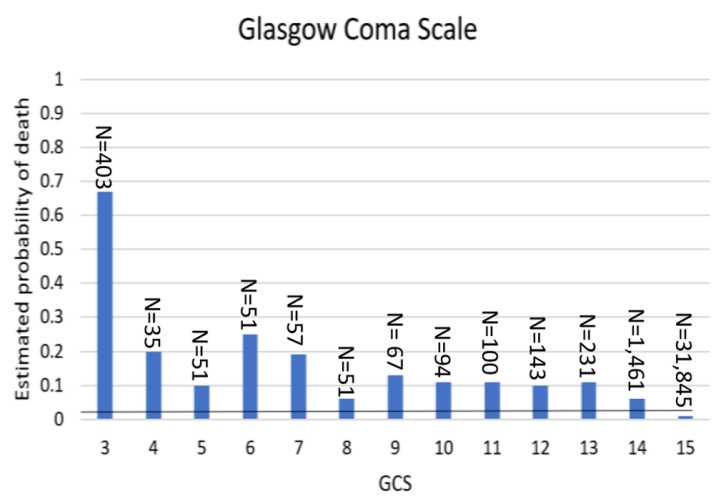

Figure 2 (A-F) Restricted cubic splines for vital values describing estimated probability of 7-day mortality, and bar chart of 7day mortality for Glasgow Coma Scale (GCS).

high temperature on arrival $\left(>39.9^{\circ} \mathrm{C}\right)$ our results indicated an increase according to short-term mortality. Our increased risk threshold according to saturation $(<97 \%)$ almost resembled the target saturation for actively treated patients, ${ }^{53}$ was equal to the saturation reported for most asymptomatic adults in an ED setting ${ }^{54}$ and supported the statement that healthy patients cannot, by an act of will, lower their saturation below $95 \% .^{55}$ A GCS score $<15$ was demonstrated to be associated with death, ${ }^{11}$ which was in accordance with threshold.
Our threshold for creatinine was lower than the thresholds in classifications for acute kidney injury or acute renal failure ${ }^{5657}$ where the classification baseline creatinine was based on patients without known kidney disease, whereas these patients were included in our analyses, and the threshold according to platelets was almost in accordance with reference intervals. ${ }^{58}$

The missing focus on lower or upper thresholds according to values as RF, systolic blood pressure, creatinine, $\mathrm{PaO}_{2}$ and platelets might represent the fact that very 
Table 2 Summary statistics of thresholds of 7-day mortality at 2.5\%

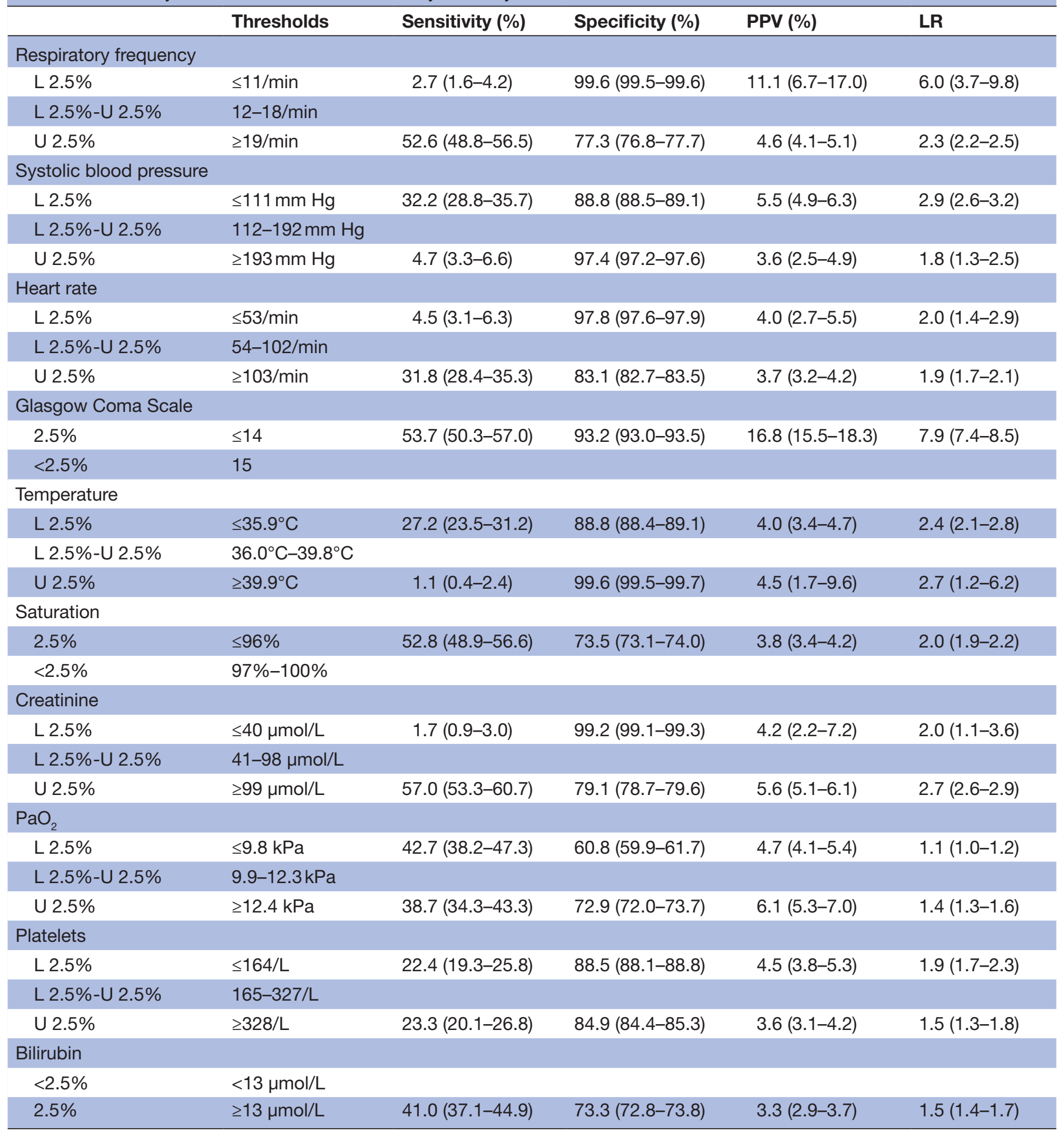

L, Lower; LR, likelihood ratio; PPV, positive predictive value; U, Upper.

few patients in an acute setting present with extremely low RF or creatinine level, or high systolic blood pressure, platelets or even $\mathrm{PaO}_{2}$ levels.

\section{Perspectives}

In the clinical setting optimal thresholds of vital and laboratory values depend on the situation and the importance of false-positive and false-negative results. Furthermore, thresholds according to individual values and risk stratification scores depend on the setting, and some scores and thresholds are developed outside the $\mathrm{ED}^{50}$ and are very time consuming and require many clinical and laboratory parameters. ${ }^{3742}$ Lower thresholds result in higher sensitivity often at the expense of specificity, but high sensitivity might be preferred to rule out dangerous conditions, 


\section{A: Creatinine}

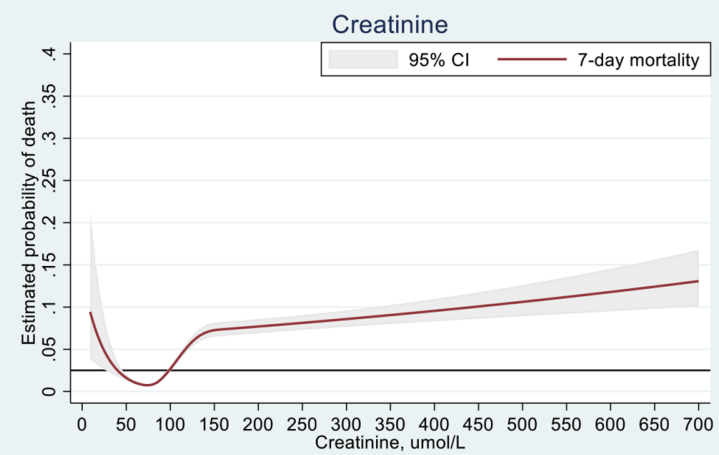

C: Bilirubin

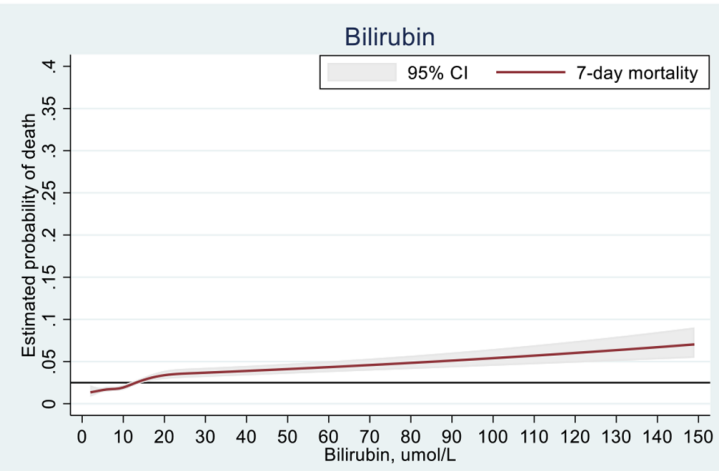

B: Platelets

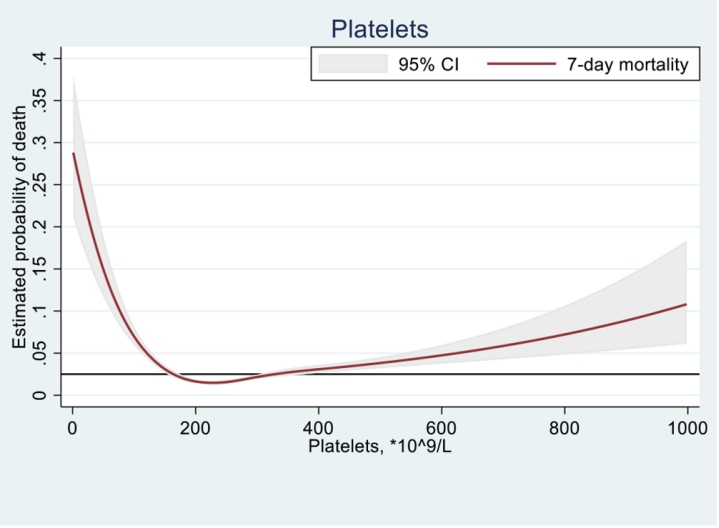

D: $\mathrm{PaO} 2$

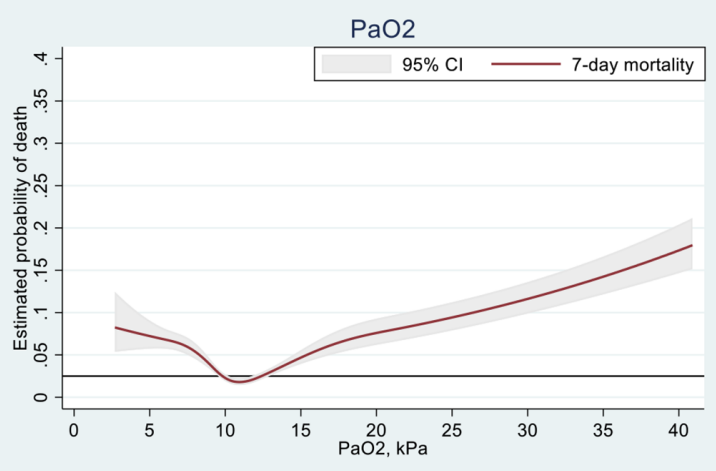

Figure 3 (A-D) Restricted cubic splines for laboratory values describing estimated probability of 7-day mortality.

and afterwards high specificity can be used to point out patients at high risk, a recent example often referred to is the differences between the prognostic scores qSOFA (quick Sequential Organ Failure Assessment) and SIRS (Systemic Inflammatoric Response Syndrome). ${ }^{59} 60$ Furthermore, the point of intersection for different variables or scores is of big importance for the sensitivity and specificity according to selected outcome, ${ }^{506162}$ and for the individual patient the risk of mortality in percentages might not be important, but the right treatment at the right time is. ${ }^{42}$ The difference on reference values and decision thresholds are important, reference intervals are often based on healthy individuals in different situations, whereas thresholds for decisions are decided based on needed or desired sensitivity and specificity according to a specific outcome. ${ }^{63}$

On an individual patient level, we might need to pay attention to patients who do not present with big risk based on reference intervals, scores or systems. According to our study, looking at the state of a patient based on vital and laboratory values is fluctuating and clear-cut thresholds defining in risk of mortality do not exist. Prognosis is also a high degree related to demographic characteristics as well as functional status. This study focused on the increased risk thresholds according to single values and not to present a new triage or risk stratification system, to shift focus to the omnipresent parameters in the acute setting and use these to point out which patients we might need to pay extra attention to.

\section{Strengths}

The study included all acutely ill adult patients with an incident contact within a 3-year study period. The patients were included on arrival and represented a very diverse group of conditions and diseases. A clearly defined catchment area, with only one hospital, where we were able to gather information on all included patients and based on the comprehensive Danish registers, we were able to present $100 \%$ follow-up. Furthermore, we performed manual review of all electronic records with missing data to minimise risk of selection bias.

\section{Limitations}

Some data on vital values were missing, despite all patients in this cohort were to be triaged. Due to the organisational structure of the ED, some patients, but not all, had their blood tests performed, and a few patients had their arterial blood gases performed after clinical evaluation. We have no clear definition on when or why and no data on supplementary oxygen treatment.

Data presented indicated that data were not missing at random but represented different levels of selection bias, 
and missing data showed a tendency of association with short-term mortality.

Furthermore, there are some limitations regarding generalisability. It was a single-centre study. The results were generalisable to other populations and ED settings that treat acutely ill adult patients on arrival, and where the organisations resemble the description outlined in the Methods section but might be less representative for ED populations in other healthcare settings.

Finally, due to lack of information in our data set, we had no data on treatment on arrival, which could affect the vital and laboratory values included. This included oxygen supplementation, fluid administration, intubation, and so on performed prehospital or on arrival.

\section{CONCLUSION}

Among adult ED patients' vital values on arrival, outside the normal ranges for the measures, are indicative of increased risk of short-term mortality, and most of the value thresholds were included in the lowest urgency level in triage and risk stratification scoring systems.

Knowledge of this is of value for clinicians in the ED as well as for clinical staff in the prehospital setting, and this could guide, or be incorporated as part of decisionmaking on patient arrival, to point out which patients need attention despite low triage and no symptoms indicating life-threatening condition.

\section{Author affiliations}

${ }^{1}$ Department of Emergency Medicine, Odense University Hospital, Odense C, Denmark

${ }^{2}$ Department of Endocrinology and Internal Medicine, Aarhus University Hospital, Aarhus, Denmark

${ }^{3}$ Department of Clinical Biochemistry and Pharmacology, Odense University Hospital, Odense C, Denmark

${ }^{4}$ Department of Emergency Medicine, Hospital of South West Jutland, Esbjerg, Denmark

${ }^{5}$ Institute of Clinical Research, University of Southern Denmark, Odense C, Denmark

\section{Twitter Daniel Pilsgaard Henriksen @dphdk}

Contributors PBP, ATL, MB and DPH contributed to the development of this study and wrote the paper. PBP analysed the data. All authors have read and approved the final manuscript.

Funding The authors have not declared a specific grant for this research from any funding agency in the public, commercial or not-for-profit sectors.

Competing interests None declared.

Patient consent for publication Not required.

Ethics approval The study was approved by the Danish Health and Medicines Authority (J No 3-3013-1070/1) and the Danish Data Protection Agency (J No 200858-0035) in compliance with the Danish law. No further approval is required for register-based studies in Denmark.

Provenance and peer review Not commissioned; externally peer reviewed.

Data availability statement Data are available upon reasonable request. Due to Danish law on personal data, data are not publicly available. Access involves approval from the Danish Data Protection Agency. On reasonable request the data are accessible through communication with corresponding author and the Research Service at the Department of Clinical Research, University of Southern Denmark.

Supplemental material This content has been supplied by the author(s). It has not been vetted by BMJ Publishing Group Limited (BMJ) and may not have been peer-reviewed. Any opinions or recommendations discussed are solely those of the author(s) and are not endorsed by BMJ. BMJ disclaims all liability and responsibility arising from any reliance placed on the content. Where the content includes any translated material, BMJ does not warrant the accuracy and reliability of the translations (including but not limited to local regulations, clinical guidelines, terminology, drug names and drug dosages), and is not responsible for any error and/or omissions arising from translation and adaptation or otherwise.

Open access This is an open access article distributed in accordance with the Creative Commons Attribution Non Commercial (CC BY-NC 4.0) license, which permits others to distribute, remix, adapt, build upon this work non-commercially, and license their derivative works on different terms, provided the original work is properly cited, appropriate credit is given, any changes made indicated, and the use is non-commercial. See: http://creativecommons.org/licenses/by-nc/4.0/.

\section{ORCID iDs}

Peter Bank Pedersen http://orcid.org/0000-0002-2831-674X

Annmarie Touborg Lassen http://orcid.org/0000-0003-4942-6152

\section{REFERENCES}

1 Bech CN, Brabrand M, Mikkelsen S, et al. Risk factors associated with short term mortality changes over time, after arrival to the emergency department. Scand J Trauma Resusc Emerg Med 2018;26:29.

2 Merz TM, Etter R, Mende L, et al. Risk assessment in the first fifteen minutes: a prospective cohort study of a simple physiological scoring system in the emergency department. Crit Care 2011;15:R25.

3 Barfod C, Lauritzen MMP, Danker JK, et al. Abnormal vital signs are strong predictors for intensive care unit admission and inhospital mortality in adults triaged in the emergency department - a prospective cohort study. Scand J Trauma Resusc Emerg Med 2012;20:28.

4 Nordberg M, Lethvall S, Castrén $M$. The validity of the triage system adapt. Scand J Trauma Resusc Emerg Med 2010;18:P36.

5 Walston JM, Cabrera D, Bellew SD, et al. Vital signs predict Rapid-Response team activation within twelve hours of emergency department admission. West J Emerg Med 2016;17:324-30.

6 Mora JC, Schneider A, Robbins R, et al. Epidemiology of early rapid response team activation after emergency department admission. Australas Emerg Nurs J 2016;19:54-61.

7 Quinten VM, van Meurs M, Olgers TJ, et al. Repeated vital sign measurements in the emergency department predict patient deterioration within 72 hours: a prospective observational study. Scand J Trauma Resusc Emerg Med 2018;26:57.

8 Henriksen DP, Brabrand M, Lassen AT. Prognosis and risk factors for deterioration in patients admitted to a medical emergency department. PLoS One 2014;9:e94649.

9 Ljunggren M, Castrén M, Nordberg M, et al. The association between vital signs and mortality in a retrospective cohort study of an unselected emergency department population. Scand J Trauma Resusc Emerg Med 2016;24:21.

10 Bleyer AJ, Vidya S, Russell GB, et al. Longitudinal analysis of one million vital signs in patients in an academic medical center. Resuscitation 2011;82:1387-92.

11 Hong W, Earnest A, Sultana P, et al. How accurate are vital signs in predicting clinical outcomes in critically ill emergency department patients. Eur J Emerg Med 2013;20:27-32.

12 Farrohknia N, Castrén M, Ehrenberg A, et al. Emergency department triage scales and their components: a systematic review of the scientific evidence. Scand J Trauma Resusc Emerg Med 2011;19:42.

13 Widgren BR, Jourak M. Medical emergency triage and treatment system (METTS): a new protocol in primary triage and secondary priority decision in emergency medicine. J Emerg Med 2011;40:623-8.

14 Subbe CP, Kruger M, Rutherford P, et al. Validation of a modified early warning score in medical admissions. QJM 2001;94:521-6.

15 Brabrand M, Knudsen T, Hallas J, et al. The Paris score can reliably predict 7-day all-cause mortality for both acute medical and surgical patients: an international validation study. QJM 2018;111:721-5.

16 Vincent JL, Moreno R, Takala J, et al. The SOFA (sepsis-related organ failure assessment) score to describe organ dysfunction/ failure. on behalf of the Working group on sepsis-related problems of the European Society of intensive care medicine. Intensive Care Med 1996;22:707-10.

17 Knaus WA, Draper EA, Wagner DP, et al. Apache II: a severity of disease classification system. Crit Care Med 1985;13:818-29. 
18 Kellett J, Kim A. Validation of an abbreviated Vitalpac ${ }^{\top M}$ early warning score (views) in 75,419 consecutive admissions to a Canadian regional hospital. Resuscitation 2012;83:297-302.

19 von Elm E, Altman DG, Egger M, et al. The strengthening the reporting of observational studies in epidemiology (STROBE) statement: guidelines for reporting observational studies. Int J Surg 2014:12:1495-9.

20 Vandenbroucke JP, von Elm E, Altman DG, et al. Strengthening the reporting of observational studies in epidemiology (STROBE): explanation and elaboration. Int J Surg 2014;12:1500-24.

21 Pedersen PB, Henriksen DP, Brabrand M, et al. Prevalence of organ failure and mortality among patients in the emergency department: a population-based cohort study. BMJ Open 2019;9:e032692:22.

22 Danmarks Statistik. SØG. Available: www.statistikbanken.dk

23 Mikkelsen S, Krüger AJ, Zwisler ST, et al. Outcome following physician supervised prehospital resuscitation: a retrospective study. BMJ Open 2015;5:e006167.

24 Lindberg Søren Østergaard, Lerche la Cour J, Folkestad L, et al. The use of triage in Danish emergency departments. Dan Med Bull 2011;58:A4301.

25 Skriver C, Lauritzen MMP, Forberg JL, et al. [Triage quickens the treatment of the most sick patients]. Ugeskr Laeger 2011:173:2490-3.

26 Schmidt M, Pedersen L, Sørensen HT. The Danish civil registration system as a tool in epidemiology. Eur J Epidemiol 2014;29:541-9.

27 Schmidt M, Schmidt SAJ, Sandegaard JL, et al. The Danish national patient registry: a review of content, data quality, and research potential. Clin Epidemiol 2015;7:449-90.

28 Frank L. Epidemiology. when an entire country is a cohort. Science 2000;287:2398-9.

29 Charlson ME, Pompei P, Ales KL, et al. A new method of classifying prognostic comorbidity in longitudinal studies: development and validation. J Chronic Dis 1987;40:373-83.

30 Shepherd BE, Rebeiro PF, Caribbean, Central and South America network for HIV epidemiology. Brief report: assessing and interpreting the association between continuous covariates and outcomes in observational studies of HIV using splines. J Acquir Immune Defic Syndr 2017;74:e60-3.

31 Durrleman S, Simon R. Flexible regression models with cubic splines. Stat Med 1989;8:551-61.

32 Harrell F E. Regression modeling strategies: with applications to linear models, logistic and ordinal regression, and survival analysis, 2015.

33 Stone CJ. [Generalized Additive Models]: Comment. Statistical Science 1986;1:312-4

34 Bone R, Balk RJC. Cerra FB EA American College of chest Physicians/Society of critical care medicine consensus conference Committee: definitions for sepsis and organ failure and guidelines for the use of innovative therapies in sepsis. , 1992: 101, 1644-55.

35 Spodick DH, Raju P, Bishop RL, et al. Operational definition of normal sinus heart rate. Am J Cardiol 1992;69:1245-6.

36 Henriksen DP, Havshøj U, Pedersen PB, et al. Hospitalized acute patients with fever and severe infection have lower mortality than patients with hypo- or normothermia: a follow-up study. QJM 2016;109:473-9.

37 Vincent JL, de Mendonça A, Cantraine F, et al. Use of the SOFA score to assess the incidence of organ dysfunction/failure in intensive care units: results of a multicenter, prospective study. Working group on "sepsis-related problems" of the European Society of Intensive Care Medicine. Crit Care Med 1998;26:1793-800.

38 Carlsson L, Lind L, Larsson A. Reference values for 27 clinical chemistry tests in 70-year-old males and females. Gerontology 2010;56:259-65.

$39 \mathrm{Mu}$, Chen W, Pan B, et al. First definition of reference intervals of liver function tests in China: a large-population-based multi-center study about healthy adults. PLoS One 2013;8:e72916.

40 Cerveri I, Zoia MC, Fanfulla F, et al. Reference values of arterial oxygen tension in the middle-aged and elderly. Am J Respir Crit Care Med 1995;152:934-41.

41 Hardie JA, Vollmer WM, Buist AS, et al. Reference values for arterial blood gases in the elderly. Chest 2004;125:2053-60.

42 Rusconi AM, Coen D. Using scores in septic patients. Intern Emerg Med 2019;14:591-2.
43 Tirkkonen J, Olkkola KT, Huhtala H, et al. Medical emergency team activation: performance of conventional dichotomised criteria versus national early warning score. Acta Anaesthesiol Scand 2014;58:411-9.

44 Brabrand M, Lassen AT, Knudsen T, et al. Seven-Day mortality can be predicted in medical patients by blood pressure, age, respiratory rate, loss of independence, and peripheral oxygen saturation (the Paris score): a prospective cohort study with external validation. PLoS One 2015;10:e0122480.

45 Hooker EA, O'Brien DJ, Danzl DF, et al. Respiratory rates in emergency department patients. J Emerg Med 1989;7:129-32.

46 Seymour CW, Liu VX, Iwashyna TJ, et al. Assessment of clinical criteria for sepsis: for the third International consensus definitions for sepsis and septic shock (Sepsis-3). JAMA 2016;315:762-74.

47 Jones AE, Yiannibas V, Johnson C, et al. Emergency department hypotension predicts sudden unexpected in-hospital mortality: a prospective cohort study. Chest 2006;130:941-6.

48 Kristensen AKB, Holler JG, Mikkelsen S, et al. Systolic blood pressure and short-term mortality in the emergency department and prehospital setting: a hospital-based cohort study. Crit Care 2015;19:158.

49 Eastridge BJ, Salinas J, McManus JG, et al. Hypotension begins at $110 \mathrm{~mm} \mathrm{Hg:} \mathrm{redefining} \mathrm{"hypotension"} \mathrm{with} \mathrm{data.} \mathrm{J} \mathrm{Trauma}$ 2007;63:291-9.

50 Seymour CW, Cooke CR, Heckbert SR, et al. Prehospital systolic blood pressure thresholds: a community-based outcomes study. Acad Emerg Med 2013;20:597-604

51 Laupland KB, Zahar J-R, Adrie C, et al. Determinants of temperature abnormalities and influence on outcome of critical illness. Crit Care Med 2012;40:145-51.

52 Khodorkovsky B, Youssef E, Adamakos F, et al. Does initial temperature in the emergency department predict outcomes in patients admitted for sepsis? J Emerg Med 2018;55:372-7.

53 Smith GB, Prytherch DR, Watson D, et al. Spo2 values in acute medical admissions breathing air-Implications for the British thoracic Society guideline for emergency oxygen use in adult patients? Resuscitation 2012;83:1201-5.

54 Witting MD, Scharf SM. Diagnostic room-air pulse oximetry: effects of smoking, race, and sex. Am J Emerg Med 2008;26:131-6.

55 Kellett J. The Assessment and Interpretation of Vital Signs. In: DeVita MA, Hillman K, Bellomo R, et al, eds. Textbook of rapid response systems: concept and implementation. Cham: Springer International Publishing;, 2017: 63-85.

56 Bellomo R, Ronco C, Kellum JA, et al. Acute renal failure - definition, outcome measures, animal models, fluid therapy and information technology needs: the Second International Consensus Conference of the Acute Dialysis Quality Initiative (ADQI) Group. Crit Care 2004;8:R204-12.

57 Mehta RL, Kellum JA, Shah SV, et al. Acute kidney injury network: report of an initiative to improve outcomes in acute kidney injury. Crit Care 2007;11:R31.

58 Biino G, Santimone I, Minelli C, et al. Age- and sex-related variations in platelet count in Italy: a proposal of reference ranges based on 40987 subjects' data. PLoS One 2013;8:e54289.

59 Franchini S, Scarallo L, Carlucci M, et al. Sirs or qSOFA? is that the question? clinical and methodological observations from a meta-analysis and critical review on the prognostication of patients with suspected sepsis outside the ICU. Intern Emerg Med 2019;14:593-602.

60 Liu Y-C, Luo Y-Y, Zhang X, et al. Quick sequential organ failure assessment as a prognostic factor for infected patients outside the intensive care unit: a systematic review and meta-analysis. Intern Emerg Med 2019;14:603-15.

61 Singer M, Deutschman CS, Seymour CW, et al. The third International consensus definitions for sepsis and septic shock (Sepsis-3). JAMA 2016;315:801-10.

62 Levy MM, Fink MP, Marshall JC, et al. 2001 SCCM/ESICM/ACCP/ ATS/SIS international sepsis definitions conference. Intensive Care Med 2003;29:530-8.

63 Sikaris KA. Physiology and its importance for reference intervals. Clin Biochem Rev 2014;35:3-14. 